\title{
Telomere length in leucocytes and solid tissues of young and aged
}

\section{rats}

\author{
M. Donatella Semeraro ${ }^{1}$, Gunter Almer ${ }^{1}$, Wilfried Renner ${ }^{1}$, Hans-Jürgen Gruber ${ }^{1}$, Markus \\ Herrmann ${ }^{1}$
}

${ }^{1}$ Clinical Institute of Medical and Chemical Laboratory Diagnostics (CIMCL), Medical University of Graz, Graz 8036, Austria

Correspondence to: Hans-Jürgen Gruber; email: hans.gruber@medunigraz.at

Keywords: telomeres, telomerase, shelterin, aging, Sprague Dawley rats

Received: December 18, 2021 Accepted: February 22, $2022 \quad$ Published: February 27, 2022

Copyright: (c) 2022 Semeraro et al. This is an open access article distributed under the terms of the Creative Commons Attribution License (CC BY 3.0), which permits unrestricted use, distribution, and reproduction in any medium, provided the original author and source are credited.

\section{ABSTRACT}

Background: Telomeres are protective nucleoprotein structures at the end of chromosomes that shorten with age. Telomere length (TL) in peripheral blood mononuclear cells (PBMCs) has been proposed as surrogate marker for $T L$ in the entire organism. Solid evidence that supports this concept is lacking.

Methods: Relative TL (RTL) was measured in PBMCS and multiple solid tissues from 24 young (4 months) and 24 aged (14 months) Sprague-Dawley (SD) rats. The mRNA expression of telomerase (TERT) and shelterin proteins TERF-1 and TERF-2 was also measured.

Results: Mean RTL in PBMCs and solid tissues of young rats ranged from $0.64 \pm 0.26$ in large intestine to $1.07 \pm$ 0.22 in skeletal muscle. RTL in PBMCs correlated with that in kidney $(r=0.315, p=0.008)$, skeletal muscle $(r=$ $0.276, p=0.022)$, liver $(r=0.269, p=0.033)$, large intestine $(r=-0.463, p=7.035 \mathrm{E}-5)$ and aorta $(r=-0.273, p=$ 0.028). A significant difference of RTL between young and aged animals was only observed in aorta (0.98 \pm 0.15 vs. $0.76 \pm 0.11, p=1.987 \mathrm{E}-6)$, lung $(0.76 \pm 0.14$ vs. $0.85 \pm 0.14, p=0.024)$ and visceral fat $(0.83 \pm 0.14$ vs. $0.92 \pm$ $0.15, p=0.44)$. The expression of TERT significantly differed between the tested organs with highest levels in liver and kidney. Age-related differences in TERT expression were found in PBMCs, skeletal muscle, and visceral fat. MRNA expression of TERF-1 and TERF-2 was tissue-specific with the highest levels in liver. Age-related differences in TERF-1 and TERF-2 expression were inconsistent.

Conclusions: The present study questions the utility of RTL in PBMCs as a biomarker for the individual assessment of aging.

\section{INTRODUCTION}

Individuals age at remarkably different rates so that the health status and functional impairment can vary widely at the same chronological age [1]. Telomere length (TL) has been proposed as a biomarker of biological age that may assist to estimate individual trajectories of aging. Telomeres are protective nucleoprotein structures at the ends of eukaryotic chromosomes that are of critical importance for the preservation of our genome [2-4]. They are composed by multiple repeats of short noncoding DNA sequences and associated proteins known as shelterins. Depending on species, the basic telomeric DNA motif is six to eight base pairs long and can be found in up to several thousand copies per telomere [5]. Telomeric DNA is double-stranded for most of its length with a short single-stranded overhang at the 3'$\mathrm{OH}$ end. Telomeric DNA and shelterin proteins form a unique three-dimensional structure, which is essential for the protective function of telomeres. With the help of shelterins, telomeric DNA folds backward forming a loop structure (t-loop) that allows the single stranded DNA-overhang to invade double-stranded telomeric DNA. Together, this prevents DNA repair systems from 
mistaking telomeric ends as DNA strand brakes and from inappropriate attempts to repair them. The complex three-dimensional structure of telomeres does also suppress the expression of genes in subtelomeric regions. This phenomenon is known as telomere positioning effect (TPE). Telomere looping does also occur over long distances so that TPEs can influence the expression of distant genes (TP-OLD) [6, 7]. Short telomeres are no longer able to maintain their complex three-dimensional structure, which abolishes TPE and TPE-OLD. As a result, formerly silenced genes become exposed and can be translated.

The progressive impairment of genomic integrity and genomic instability are key drivers of the aging process $[8,9]$. With every cell division, telomeres shorten a little bit due to incomplete replication of the DNA lagging strand. In addition, accidental damage can also cause telomere shortening. This age-related shortening progressively compromises the three-dimensional structure of telomeres and once a critical threshold is reached, cells can no longer divide $[10,11]$. Because of their progressive shortening, telomeres are considered a molecular clock of aging.

However, telomere shortening is not a linear process. Human and animal studies have repeatedly shown that lifestyle factors, such as obesity, physical activity, smoking, psychological stress, and sleep, modify the rate of telomere shortening. Furthermore, these factors are related to the risk of many age-related diseases and mortality. Telomerase (TERT), an enzyme that elongates telomeres, and shelterin proteins are key regulators of the telomere shortening rate. Previous studies suggest that many lifestyle factors modify the telomere shortening rate through an altered expression of these proteins.

The unique role of telomeres in the aging process has led to the idea that TL could be a useful surrogate marker of biological age. In fact, human and animal studies have shown that in age-related diseases, such as atherosclerosis, diabetes and rheumatic diseases, TL is reduced in the affected tissues [8, 12-15]. As the analysis of TL in solid tissues requires an invasive biopsy, TL in peripheral blood leucocytes (LTL) has been proposed as surrogate marker for TL in other tissues. However, solid evidence that supports this concept is largely lacking. A rather small study by Dlouha et al. analysed TL in twelve human tissues from deceased donors [16]. TL differed by factor six between different organs and LTL was only correlated to TL in liver and muscles. Besides a rather small number of cases, this study is strongly limited by a very wide age range of the donors ( 29 weeks to 88 years). Also, Hiam et al. reported a weak correlation between LTL and skeletal muscle TL in healthy men. However, skeletal muscle TL was not associated with age [17]. To date, the strongest evidence that supports LTL as a suitable surrogate marker for TL in other tissues is provided by the large scale GTEx project [18]. Although this study is of cross-sectional nature, the results suggest that LTL shortens at a comparable rate as other somatic cells [18]. However, specimen collection was not standardized in this study, individuals were very rather heterogeneous and information on their health status has not been obtained. A systematic mapping of TL in multiple organs and tissues of the same individual has not been performed as yet. Moreover, a structured analysis of age-related changes of TL in multiple tissues is also lacking.

Animal studies are useful to investigate age-related changes of telomeres in multiple organs of the same organism [19]. The few existing studies have focused on specific tissue types, such as leucocytes, myocardium, liver, and aorta. Similar to humans, the telomeres of murine blood leukocytes and other cell types (i.e., myocardium, liver, aorta) shorten with age [20-22], but this process may take more than a year [20, 21]. Moreover, in skeletal muscle and cardiomyocytes the age-related shortening of telomeres is accompanied by a decreased gene expression of the shelterin proteins TERF-1 and TERF-2 [22].

To address the existing gap of knowledge, the present study aimed to answer the following question. Does TL differ between leucocytes and solid organs? Is LTL correlated with TL in other organs and tissues? Does ageing induce a systematic shortening of TL in PBMCs and solid tissues? And finally, are age-related changes in TL associated with systematic changes in the expression of telomere related genes that are critical for the preservation of telomere length and structure, and telomeric function? Answering these questions will help to decide whether or not LTL is a suitable marker of biological age that represents TL in other organs of the same organism. For this purpose, we performed a systematic analysis of TL in PBMCs and multiple solid tissues from young and aged Sprague-Dawley (SD) rats. In addition, we studied the mRNA expression of telomerase (TERT) and the shelterins TERF-1 and TERF-2. All of them are established regulators of telomeric length, structure and function.

\section{RESULTS}

\section{Distribution of RTL in blood leucocytes and solid organ tissues}

Two out of twenty-four animals in the aged group had to be excluded from analysis due to illness. The 
following results describe changes in TL and expression of telomere-associated genes in the remaining 46 healthy animals. RTL showed pronounced interindividual variability across all tissues with greatest scatter in large intestine, spleen, and brain (Figure 1). The young animals had a mean RTL in PBMCs of 0.88 \pm 0.15 . Mean RTLs of the solid tissues ranged from
$0.64 \pm 0.26$ in large intestine to $1.07 \pm 0.22$ in skeletal muscle. Liver, skeletal muscle, aorta and kidney had significantly higher mean RTLs than PBMCs. In contrast, RTL in large intestine and lung was lower than in PBMCs. Aged animals exhibited a comparable distribution of RTL across organs. Similar to young animals, mean RTL in aorta and large intestine was
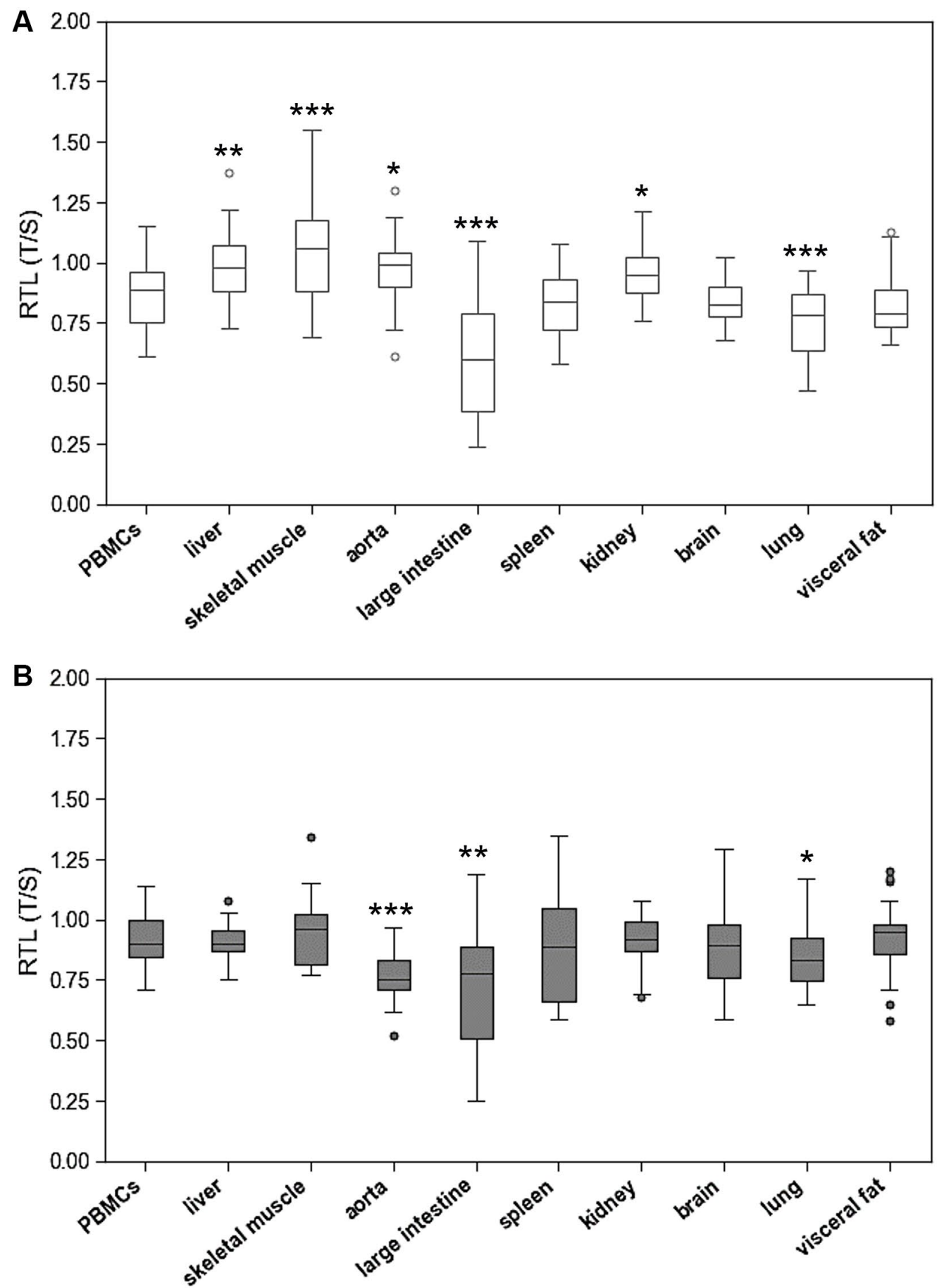

Figure 1. Relative telomere length (RTL) of peripheral blood mononuclear cells (PBMCs) compared to RTL of 9 different solid organs (including liver, skeletal muscle, aorta, large intestine, spleen, kidney, brain, lung, visceral fat) isolated from. (A) young and (B) adult rats. RTL is expressed as ratio of average telomere length to the reference gene GAPDH. ${ }^{*} p<0.05 ;{ }^{* *} p<0.01 ;{ }^{* * *} p<$ 0.001 vs. PBMCs RTL. 
significantly lower than in PBMC, whereas in lung RTL was significantly higher (Figure 1).

To test the hypothesis that RTL in PBMCs represents the situation in other organs, RTL from PBMCs and solid organs were correlated in young and aged animals. Figure 2 shows that there was no consistent correlation between RTL in PBMCs and solid organs. Significant positive correlations were found between RTL in PBMCs and liver, skeletal muscle, and kidney. Inverse
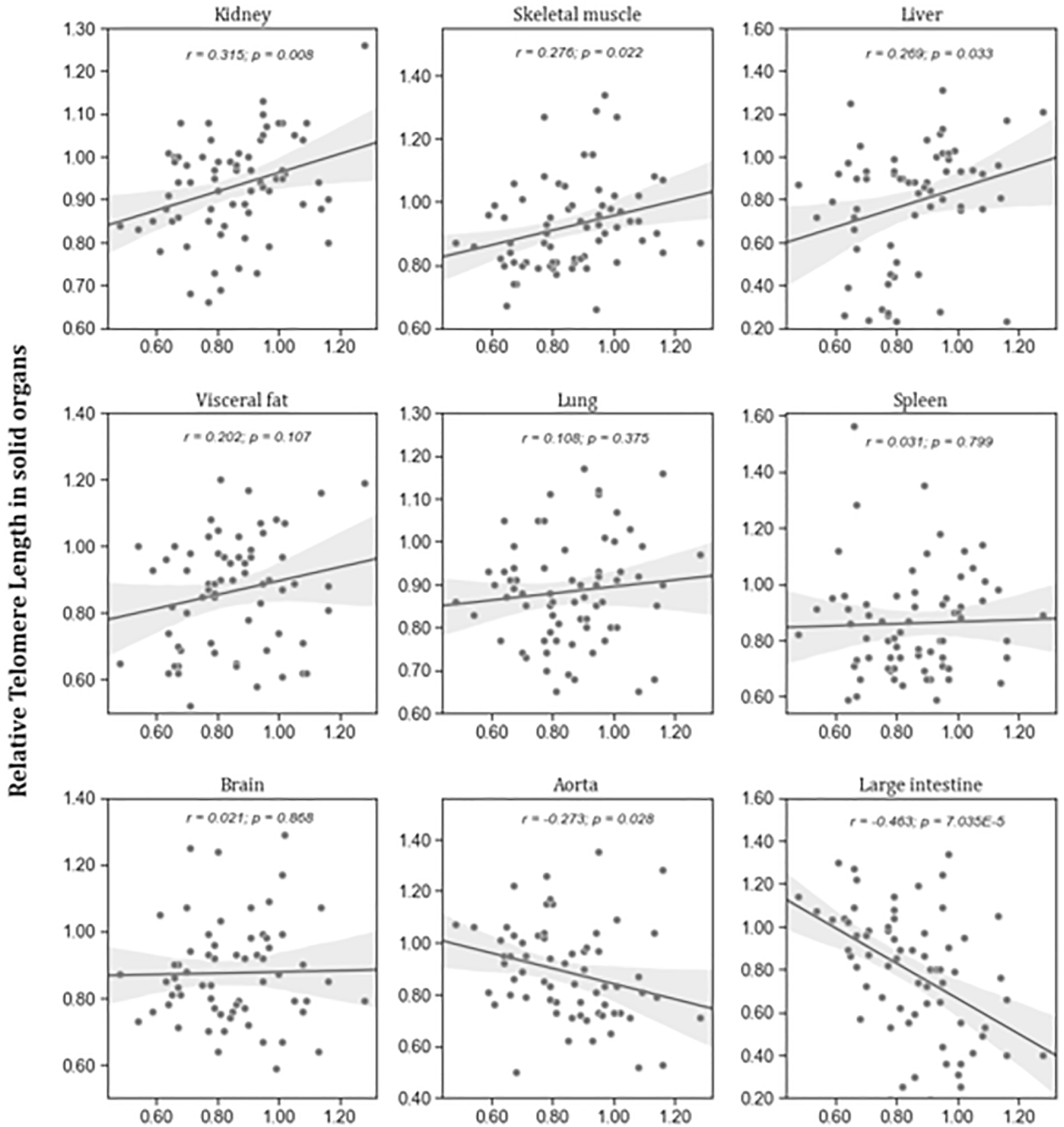

Relative Telomere Length in Peripheral Blood Mononuclear Cells

Figure 2. Correlation between RTL in PBMCs and RTL in different organs isolated from adult rats $(n=72) . r-P e a r s o n$ correlation coefficient, $p-p$ value. The figure also shows in grey the regression line and $95 \%$ confidence interval. 
correlations were found between RTL in PBMCs and RTL in large intestine and aorta. RTL of all other tissues was not correlated to that of PBMCs.

\section{Age-related changes of RTL}

To identify age-related differences of RTL in PBMCs and solid tissues, we compared RTL of aged and young animals in all these matrices (Figure 3, Supplementary Table 1). The only organ with lower RTL in aged animals was aorta. Lung and visceral fat tissue showed higher RTL in aged animals. All other organs had comparable RTL in both age groups.

\section{Telomerase and shelterin mRNA expression from different tissue types in young and adult SD rats}

The expression of TERT markedly differed between the tested organs with highest levels in liver and kidney (Figure 4). In the liver, TERT mRNA expression was 40 times higher than in spleen and lung tissue.

Age-related differences of TERT expression were only found in spleen, skeletal muscle, and visceral fat (Figure 5, Supplementary Table 1).
The mRNA expression of TERF-1 and TERF-2 was tissue specific showing pronounced variation between the different organs and spleen. The highest expression levels of both genes were found in liver (Figure 6). In addition, TERF-2 was highly expressed in brain. In six out of nine tissue types TERF-2 and TERT were positively associated with $\mathrm{r}=0.801 ; p=4,615 \mathrm{e}-11$ (spleen), $\mathrm{r}=0.560 ; p=0.00017$ (liver), $\mathrm{r}=0.707 ; p=$ 1,002e-6 (aorta), $\mathrm{r}=0.783 ; p=1,278 \mathrm{e}-10$ (large intestine), $\mathrm{r}=0.748 ; p=3,602 \mathrm{e}-9$ (kidney), $\mathrm{r}=0.562 ; p$ $=0.000106$ (lung), but not in skeletal muscle, brain, and visceral fat.

Age-related differences in mRNA expression of these two shelterins were inconsistent. In aged animals, TERF-1 showed higher mRNA expression levels in liver, kidney, and visceral fat but lower levels in lung. TERF-2 expression was higher in spleen, liver, and lung of aged animals, whereas aorta showed a lower expression level (Figure 7, Supplementary Table 1).

\section{DISCUSSION}

The systematic mapping of RTL in young and old rats showed substantial differences between organs. These

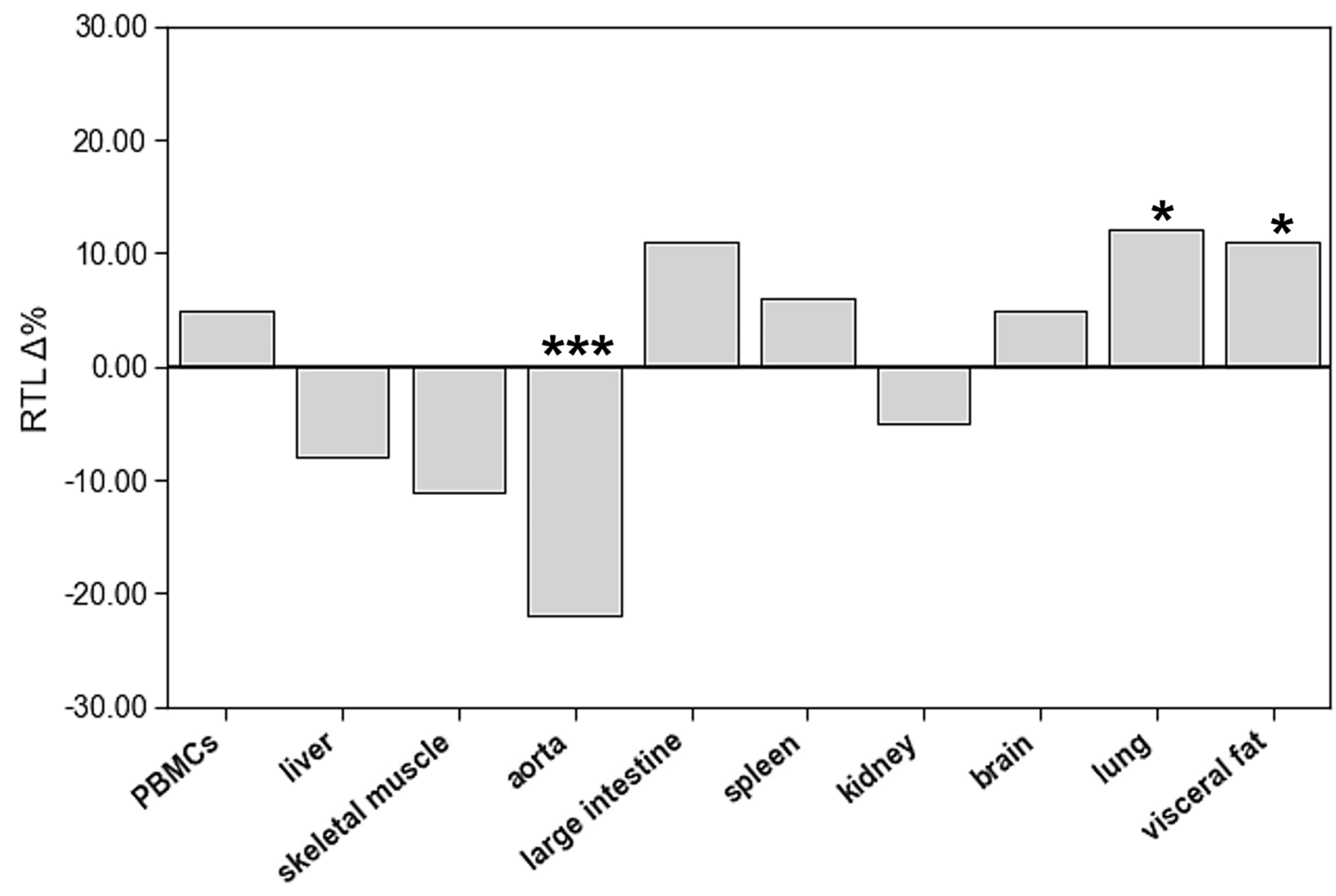

Figure 3. The impact of age on relative telomere length (RTL) of different tissue types. The boxes represent the delta\% variation of RTL in adults compared to young. ${ }^{*} p<0.05 ;{ }^{* * *} p<0.001$ vs. young. 
differences were accompanied by pronounced interindividual variability of RTL in all tissues. Surprisingly, the distribution of RTL across different organs was comparable in young and aged animals without a systemic age-related reduction. Furthermore, correlation analyses showed no consistent association between RTL in PBMCs and solid tissues. Together, these results question the utility of RTL of PBMCs as a valid biomarker that represents the aging process in the entire organism.

Does TL between leucocytes and solid organs? The present study provides robust evidence for tissue specific RTLs. In SD rats, the longest and the shortest telomeres were found in skeletal muscle and large intestine, respectively, with a 2 -fold difference. To date,
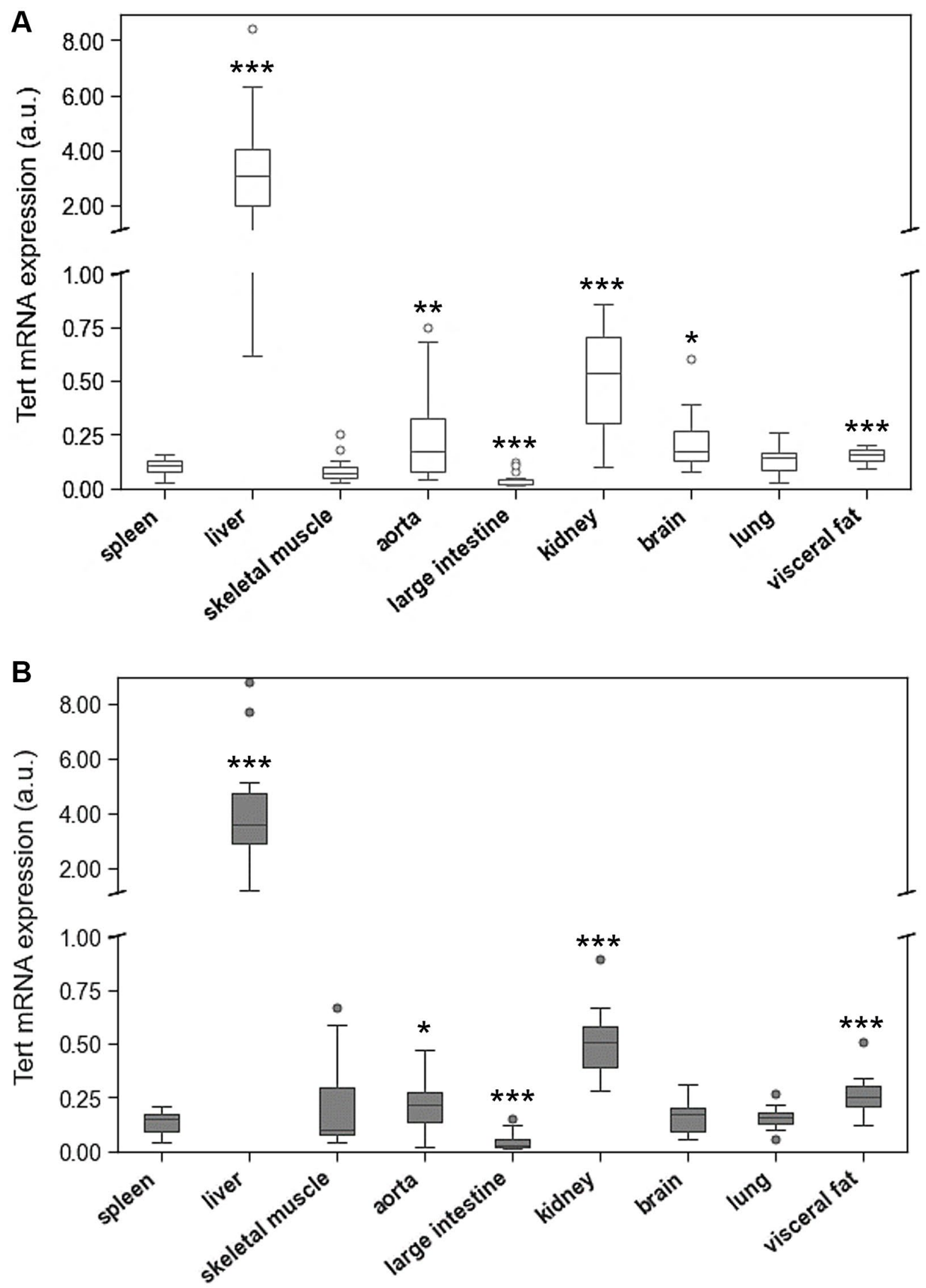

Figure 4. Tert mRNA expression of spleen compared to Tert mRNA expression of 8 different solid organs (including liver, skeletal muscle, aorta, large intestine, kidney, brain, lung, visceral fat) isolated from. (A) young and (B) adult rats. Tert mRNA expression is shown in arbitrary units. ${ }^{*} p<0.05 ;{ }^{* *} p<0.01 ;{ }^{* * *} p<0.001$ vs. spleen Tert mRNA expression. 


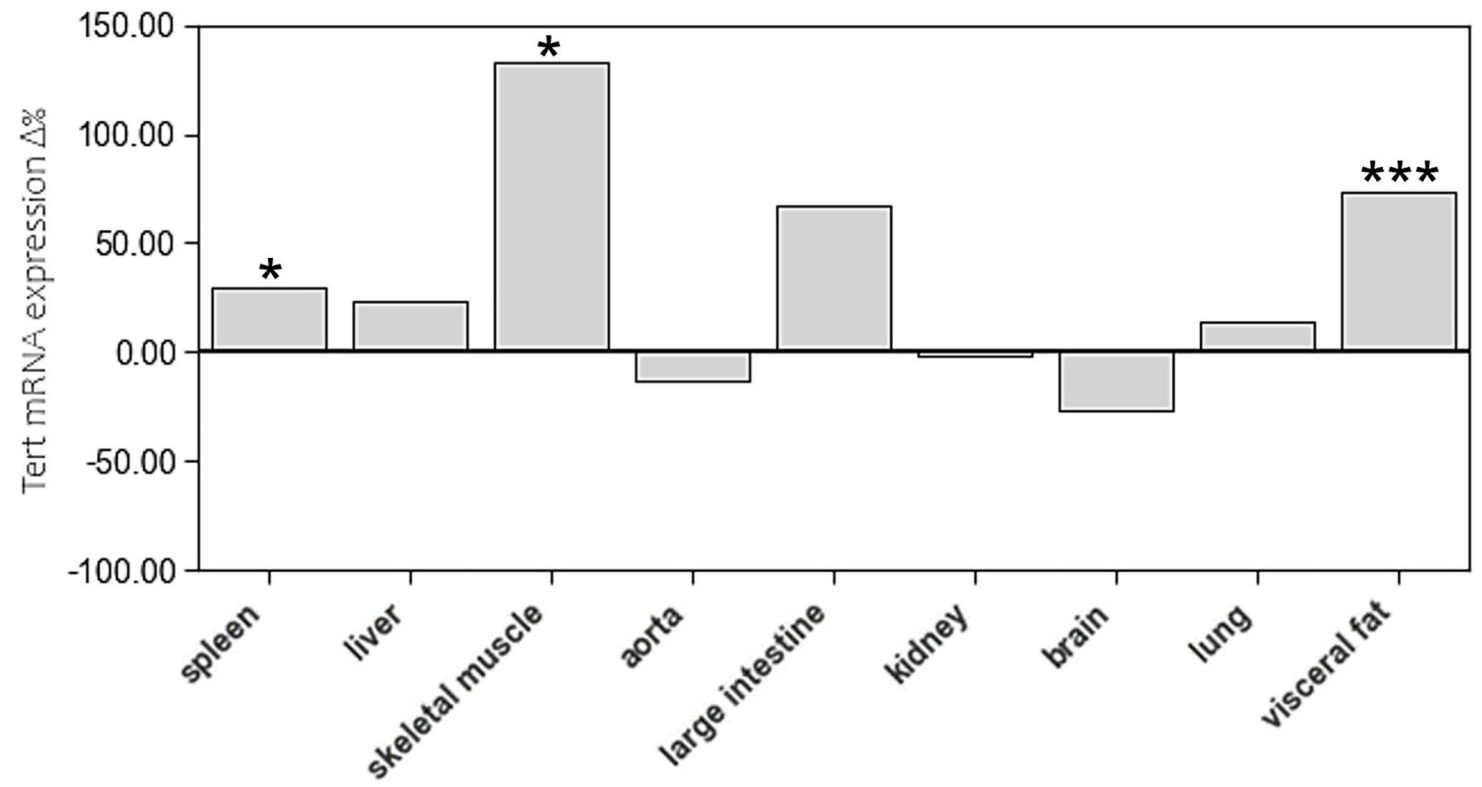

Figure 5. The impact of age on Tert mRNA expression of different tissue types. The boxes represent the delta\% variation of Tert mRNA expression in adults compared to young. ${ }^{*} p<0.05 ;{ }^{* * *} p<0.001$ vs. young.
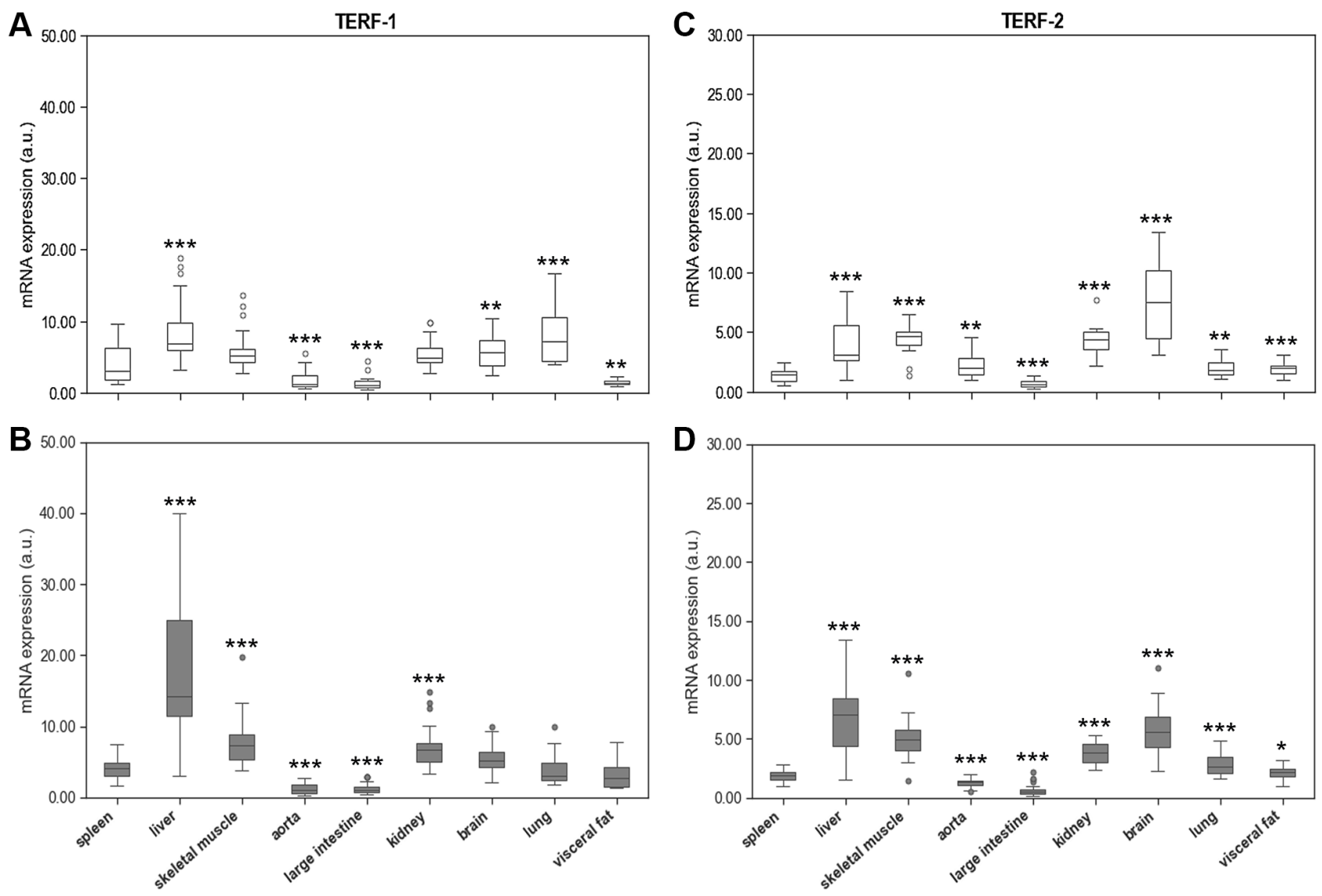

Figure 6. Spleen Terf-1 mRNA expression compared to Terf-1 mRNA expression of 8 different solid organs (including liver, skeletal muscle, aorta, large intestine, kidney, brain, lung, visceral fat) isolated from. (A) young and (B) adult rats. Spleen Terf-2 mRNA expression compared to Terf-2 mRNA expression of 8 different solid organs (including liver, skeletal muscle, aorta, large intestine, kidney, brain, lung, visceral fat) isolated from: (C) young and (D) adult rats. Terf-1 and Terf-2 mRNA expression is shown in arbitrary units. ${ }^{*} p<0.05 ;{ }^{* *} p<0.01 ;{ }^{* * *} p<0.001$ vs. spleen Terf-1 or Terf-2 mRNA expression. 
similar studies have not been performed in rodents. Human studies that compared RTL between organs also found significant differences of up to 2.5 -fold $[16,18]$. In a rather small study by Dlouha et al, leucocytes showed the longest telomeres, whereas liver, brain and skin exhibited the shortest telomeres [16]. However, this study analysed only samples from twelve individuals with a very wide age-range of 29 weeks to 88 years, which limits the robustness of the results. In a much larger study of 6391 tissue samples from 952 donors, Demanelis et al. found the shortest telomeres in leucocytes and the longest ones in testis, skeletal muscle, and colon [18]. The organ distribution of RTL in rats and humans seems to differ substantially, which is probably due to species-effects. Despite, rigorous standardization of age, genetic background and housing conditions, the animals of the present study displayed great interindividual variation in RTL, which was similar to that observed in the human studies discussed before.

Is LTL correlated with TL in other organs and tissues? In contrast to current concepts, RTL in PBMCs was positively correlated to kidney, skeletal muscle, and
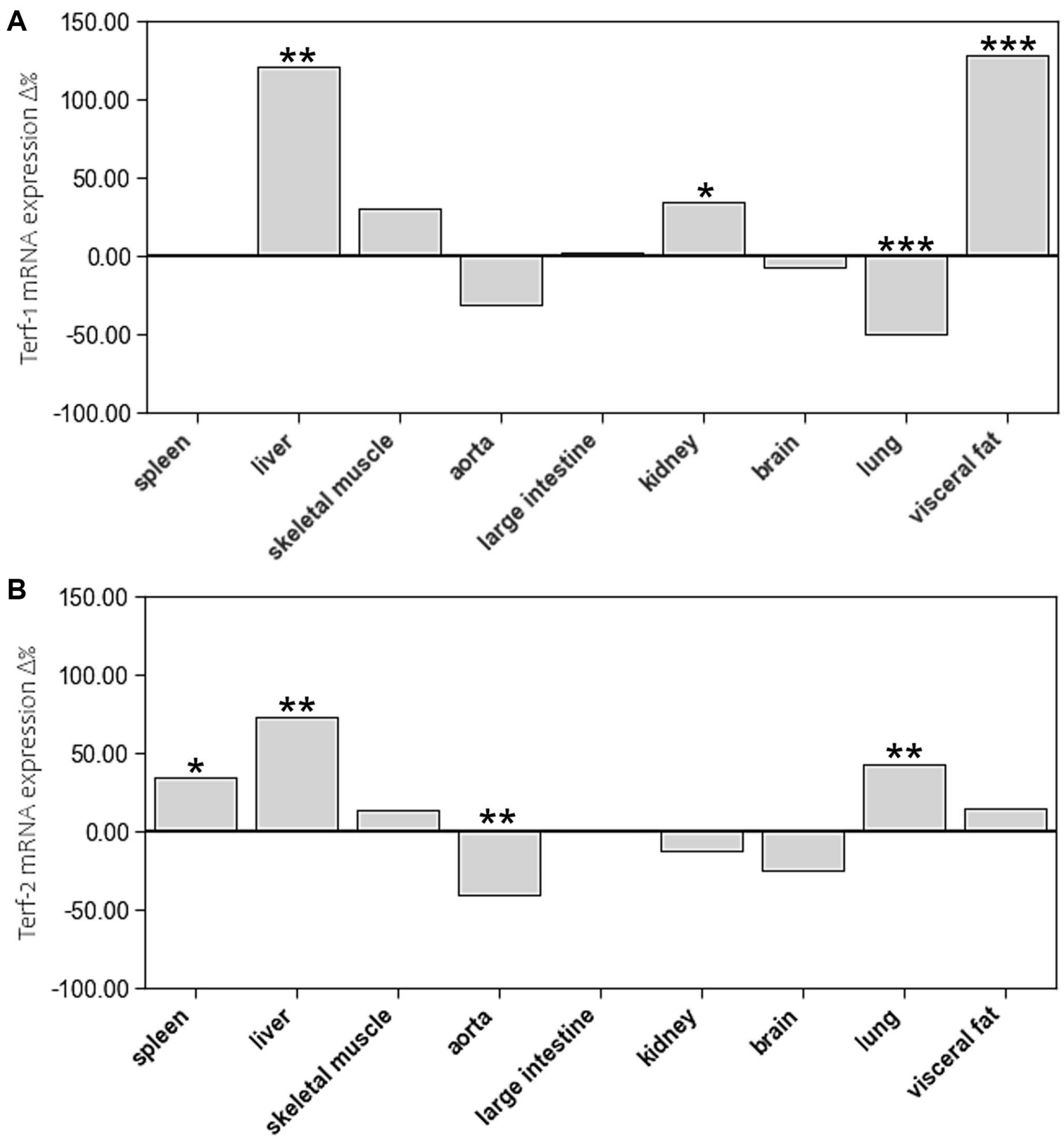

Figure 7. The impact of age on mRNA expression of (A) Terf-1 and (B) Terf- 2 in different tissue types. The boxes represent the delta\% variation of mRNA expression of Terf-1 and Terf- 2 in adults compared to young. ${ }^{*} p<0.05 ;{ }^{* *} p<0.01 ;{ }^{* * *} p<0.001$ vs. young. 
liver but not to any of the other tissue types. In some tissues, such as large intestine and aorta, we even observed an inverse correlation. However, our results are aligned to those from others, Dlouha et al. also found a significant correlation of RTL in leucocytes with that in liver and muscle [16]. Moreover, in blood leucocytes and skeletal muscle biopsies of 93 healthy men between 18-87 years of age, Hiam et al. showed a weak, but significant, correlation of RTL [17]. In the large scale GTEx project, Demanelis et al. reported that RTLs were positively correlated amongst different tissues and that whole blood RTL was a reasonable surrogate for RTL in most tissues [18]. Inverse associations, as observed by Dlouha et al. in humans and us in rats, may thus be chance findings that are primarily due to the marked interindividual variability of RTL in most tissues. Based on previous studies and the present result it appears that RTL in peripheral blood cells is not a suitable biomarker to judge RTL in other organs of the same individual. However, in large cohorts there may be a robust association between RTL in peripheral blood cells and most other tissue types, which makes this an interesting marker for epidemiologic aging studies.

Does ageing induce a systematic shortening of TL in PBMCs and solid tissues? Another observation of the present study was that in most tissues RTL was comparable in young adults and aged animals. This contrasts the concept of telomere shortening with advancing age [23-26]. However, existing longitudinal studies measured RTL exclusively in leucocytes [23, 25-31]. In the large scale GTEx project, Demanelis et al. also found an age-related reduction of RTL in most tissues [18]. Here we performed a systematic analysis of RTL in multiple organs of young and aged animals that were kept under standardized conditions. Only in aortic tissue RTL was significantly lower in aged than juvenile young animals. In lung and visceral fat RTL increased with advancing age. The absence of telomere shortening in our rats could be related to their age. SD rats have a life-expectancy of 2.5 to 3.5 years. In the present study, animals were sacrificed at 14 months of age, which corresponds to mid-adult age. Therefore, it cannot be excluded that a longer aging period would have yielded a different result. Previous work from Werner et al. supports a rather slow shortening of telomeres in leucocytes and cardiomyocytes of C57/B16 mice [20, 21]. In these animals, a significant reduction of telomere length took up to 18 months. Although it was demonstrated that telomeric sequences are highly conserved among eukaryotic vertebrates, the length of telomeres differs between species [19]. While in humans, telomeres reach up to $20 \mathrm{~kb}$ in length, rodent telomere length is rather heterogeneous. For example, Mus musculus' telomers reach up to $150 \mathrm{~kb}$ in size [32].
Rats instead have telomeres ranging from 20 to $100 \mathrm{~kb}$ in length [33]. Therefore, the present results apply to healthy SD rats only.

Large scale human studies have also provided robust evidence that longitudinal changes of RTL vary substantially between individuals $[23,24,26]$. For example, amongst 4053 adults that were analysed at baseline and again after 7-8 years, LTL decreased in $66.3 \%$, did not change in $11.2 \%$ and increased in $22.5 \%$ [26]. Such heterogeneous results may be due to multiple individual factors that influence telomere dynamics, such as stress, nutrition, physical activity, smoking and others [13, 34-44]. In the present animal study, most of these factors were rigorously controlled. Moreover, we analysed 10 different tissues without seeing a systematic effect. Together with existing human studies, the present results indicate that neither RTL in PBMCs nor in solid tissues is a useful marker to monitor aging on an individual level. Only in cohorts of substantial size, age-related changes of RTL can be shown reliably.

It is important to consider that existing studies have measured telomere length primarily by qPCR, which provides an average RTL across all cells and chromosomes in the sample [45]. However, there is substantial evidence that only the shortest telomeres trigger DNA damage responses and induce senescence. Information on the shortest telomeres can only be obtained by much more sophisticated methods, such as Telomere Shortest Length Assay (TeSLA) or Quantitative Fluorescence In-Situ Hybridization (QFISH). The characteristics and caveats of available methods for the analysis of telomere length have been summarized by Aubert $\mathrm{G}$ et al. and Lai TP et al. [45, 46]. Another important aspect is that RTL may vary within the same organ depending on the site of specimen collection. In most organs the distribution of specific cell populations is not homogenous so that regional differences may impact the results.

Are age-related changes in TL associated with systematic changes in the expression of telomere related genes? An organ specific regulation of telomeric function is further supported by the mRNA expression analyses of TERT, TERF-1 and TERF-2. Liver tissue showed by far the highest TERT mRNA expression. However, this phenomenon was not accompanied by markedly longer telomeres. Considering that hepatocytes divide rapidly, it can be assumed that the high expression of TERT is needed to prevent excessive telomere shortening in these cells. Also, TERF-1 and TERF-2 are highly expressed in hepatic tissue supporting a tissue specific maintenance of telomeres in the liver. In contrast, terminally differentiated tissues, such as skeletal muscle and brain, are characterized by a 
low expression level of TERT and TERF-1, but a rather high expression of TERF-2. TERF-2 is pivotal for tloop formation and aids the invasion of the singlestranded telomeric DNA overhang into the doublestranded telomeric region upstream. Loss of TERF-2 has been shown to prevent t-loop formation and leads to excessive telomere shortening with premature cell death [47]. It can be speculated that the high TERF-2 expression in terminally differentiated tissues reflects the particular need to protect their telomeres from DDR.

In the present study, we have not seen systematic agerelated differences in mRNA expression of these proteins. TERT expression was slightly higher in spleen, skeletal muscle, and visceral fat of the aged animals, but not in any of the other tissues. When considering the interindividual variability of TERT expression in most tissues, the physiological relevance of these differences is questionable. However, TERF-1 and TERF-2 expression was markedly higher in aged liver tissue, which further supports the concept of an organ specific maintenance of telomere homeostasis in rapidly dividing hepatocytes. In addition, TERF-2 expression was higher in spleen and lung tissue of aged animals, which also have a great capacity of renewal. Interestingly, aortic tissue showed a substantially lower TERF-2 expression in aged animals, which was paralleled by a reduction in RTL. Considering the rather inconclusive results of TERF-1 and TERF-2 expression, caution is warranted when interpreting them in relation to TERT and RTL. All of the above-mentioned concepts are speculative and require further research to prove them.

There are several limitations that have to be considered when interpreting the present results. Our results and conclusion exclusively apply to healthy SD rats and cannot simply be translated to the situation in various diseases or other species. A study duration of ten months with rodents is rather long but may be insufficient to capture significant age-related effects on telomeres. Considering the life expectancy of SD rats, an observation period of two years might better reflect changes in telomere biology. However, towards the end of our study, some animals started developing tumours and thus had to be excluded from the analysis. This implies that for a longer study more animals would be needed in order to obtain a sufficient number of aged animals that are free from tumours and other relevant diseases. Furthermore, we performed only one measurement per animal and tissue type, which leaves room for random effects due to regional differences in RTL. In addition, solid organ tissues cannot be collected longitudinally. Therefore, we chose a cross-sectional study design. Also, the PCR based method for RTL analysis harbours several limitations. As a relative method that requires the simultaneous measurement of a single copy reference gene, this approach is subject to greater technical variability than direct methods. Furthermore, it only provides an average TL across all telomeres. Information on the distribution of short and long telomeres can only be obtained from more sophisticated methods that are not feasible for the analysis of large sample sets. The importance of this aspect is nicely shown by a recent study from Cherif et al. that investigated gender-related lifespan differences in Wistar rats. When using a modified terminal restriction fragments (TRF) method that analysed the percentage distribution of TRFs in different ranges of restriction fragment length, they found slightly longer leucocyte telomeres in females than in males. In addition, they observed subtle gender differences in several solid organs including kidney, liver, lung, and pancreas. These differences could not be detected with the mean TRF of the traditional method [19]. Through a robust number of animals per group we aimed to compensate for most of the confounding factors. Despite rigorous standardization of the experimental conditions, this number may still be too low to demonstrate similar effects as in epidemiologic cohort studies.

\section{MATERIALS AND METHODS}

\section{Animal model}

Forty-eight female Sprague Dawley (SD) rats were purchased from Janvier Labs (Le Genest-Saint-Isle, France) at four months of age. All animals were fed a standard chow-based diet and kept on a $12 \mathrm{~h} / 12 \mathrm{~h}$ light/dark cycle at the core facility animal housing at the Medical University of Graz (Austria). Temperature was maintained between 22 and $25^{\circ} \mathrm{C}$. Humidity ranged between 55 to $58 \%$. After one week of acclimatization, half of the animals were sacrificed at young age $(n=$ 24). The other half was euthanatized after ten months. At the time of scarification, blood was collected by heart puncture into plasma-EDTA and serum tubes (Sarstedt, Nümbrecht, Germany) under deep isoflurane anaesthesia (Forane, Abbott, Austria). After centrifugation at $2000 \mathrm{~g}$ for $12 \mathrm{~min}$ at room temperature, plasma and serum samples were aliquoted and stored at $-80^{\circ} \mathrm{C}$ until batched analysis. Immediately after blood collection, the following organs were explanted and snap frozen in liquid nitrogen: liver, skeletal muscle, heart, aorta, large intestine, spleen, kidney, brain, lung, visceral fat. Subsequently, all tissue samples were stored together deep-frozen at $-80^{\circ} \mathrm{C}$ until analysis. Exclusion criteria were the development of illnesses or tumours during the intervention period. Two animals of the aged group were excluded from the study. 


\section{Analysis of relative telomere length (RTL) in PBMCs and solid organs}

After diluting $100 \mu \mathrm{l}$ of whole blood with $100 \mu \mathrm{l}$ of $\mathrm{dH}_{2} \mathrm{O}$, DNA was isolated with the MagNA Pure LC instrument (Roche, Austria) using the Total Nucleic Isolation Kit (Roche, Austria). Subsequently, relative telomere length (RTL) of peripheral blood mononuclear cells (PBMCs) was measured by quantitative real-time PCR (qPCR) using a protocol developed by Cawthon [48].

This assay quantifies the ratio of average TL (T) to glyceraldehyde-3-phosphate dehydrogenase (GAPDH) as single copy reference gene (S). The single copy gene is used as amplification control for each sample and to determine the number of genome copies per sample. All qPCR analyses were performed on Thermocycler CFX384 TouchTM (Biorad, Germany) instrument using the following primers:

- Telomere Forward: 5'-CGGTTTGTTTGGGTTTGG GTTTGGGTTTGGGTTTGGGTT-3';

- Telomere Reverse: 3'-GGCTTGCCTTACCCTTAC CCTTACCCTTACCCTTACCCT-5';

- GAPDH Forward: 5'-CACCTAGACAAGGATGCA GAG-3';

- GAPDH Reverse: 3'-GCATGACTGGAGGAATCA CA-5'.

All primers have been purchased from Eurofins Genomics, Austria. Each run included a standard curve made by dilutions of isolated and pooled rat DNA from 21 different blood samples, to determine the quantity of the targeted templates. RTL has been calculated as the ratio of telomere quantity to single copy reference gene quantity ( $\mathrm{T} / \mathrm{S}$ ratio).

RTL in solid organs was analysed with the same method described before. For this purpose, approximately $10 \mathrm{mg}$ of tissue were homogenized in $300 \mu 1$ Magna Pure Lysis Buffer (Roche, Austria) using the MagnaLyser (Roche, Austria). Subsequently, the DNA was isolated and quantified using the same procedure as for blood leucocytes.

The mRNA expression analyses in blood cells and solid organs

TERT, TERF-1, and TERF-2 gene expression was analysed in RNA extracts of all solid organs. As blood leucocytes were used up for the measurement of RTL, they were not available for mRNA expression analyses. Therefore, mRNA expression in spleen was used as reference because the organ belongs to the lymphatic system and is rich in leucocytes. From each organ,
$10 \mathrm{mg}$ of tissue were homogenised in $300 \mu \mathrm{l}$ Magna Pure Lysis Buffer (Roche, Austria) using the MagnaLyser (Roche, Austria). RNA was extracted from these homogenates with the Total Nucleic Isolation Kit (Roche, Austria) on a MagNA Pure LC instrument (Roche, Austria). Subsequently, the mRNA in these extracts was transcribed into cDNA using the QuantiTect Reverse Transcription kit (Qiagen, Germany). Finally, mRNA expression of TERT, TERF-1, and TERF-2 was analysed by qPCR with TaqMan probes (Life Technologies dba Invitrogen, United States). The expression of each target gene expression was calculated with the $\Delta \Delta C \mathrm{C}$ method using $\beta$-actin as reference gene. The sequences of the probes used were as follows:

- B-actin: 5'-CTTCCTTCCTGGGTATGGAATCC TG-3';

- Tert: 5'-ATCGAGCAGAGCATCTCCATGAA TG-3';

- Terf-1: 5'-AAAACAGACATGGCTTTGGGAAG AA-3';

- Terf-2: 5'-GAGAAAATTTAGACTGTTCCTTT GA-3'.

\section{Statistical analyses}

Results are shown as mean \pm standard deviations. Group differences were assessed using the two-tailed Student's $t$ test for dependent or independent samples or the Mann-Whitney $U$ test depending on the distribution of the data. Correlations between variables were determined by linear regression analysis according to Pearson ( $r$, Pearson Correlation coefficient; $p$, univariate ANOVA). $\quad p$ values of $<0.05$ were considered statistically significant. Data were plotted using Python programming language with Jupyter Notebook within the data science package Anaconda3 for Windows. IBM SPSS v. 26 for Windows was used for explorative data analysis and a level of acceptance of the null hypothesis was set at $p=0.05$.

\section{Institutional review board statement}

The study was approved by the responsible National Ethics Committee (GZ: 66.010/0070-V/3b/2018) and conducted in accordance with the guidelines of the Animal Care and Use Committee of the Ministry of Science and Research, Vienna, Austria.

\section{Data availability statement}

The datasets generated during and/or analysed during the current study are based on the work for a $\mathrm{PhD}$ thesis and therefore are not publicly available but are available from the corresponding author on reasonable request. 


\section{CONCLUSIONS}

In conclusion, the present study questions the utility of RTL in PBMCs as a biomarker for the individual assessment of aging. Despite rigorous standardization of housing conditions, sample collection and analytical procedures, excessive intra- and interindividual variability has been observed. Furthermore, RTL in PBMCs was not systematically correlated with solid organ tissues and no differences have been observed between young and old animals. Thus, future studies should focus on the analysis of older animals and measurement of the shortest telomeres.

\section{AUTHOR CONTRIBUTIONS}

Conceptualization, M.H., H.-J.G., and G.A.; methodology, M.D.S., G.A., and H.-J.G.; software, H.J.G., and M.D.S.; validation, W.R., and H.-J.G.; formal analysis, M.D.S., W.R., H.-J.G.; investigation, M.H., H.-J.G., M.D.S, and G.A.; resources, M.D.S., H.-J.G., and G.A; data curation, M.D.S.; writingoriginal draft preparation, M.D.S.; writing-review and editing, M.H., H.-J.G., W.R., and G.A.; visualization, M.D.S.; supervision, M.H., and H.-J.G.; project administration, M.H.; funding acquisition, M.H. All authors have read and agreed to the published version of the manuscript.

\section{ACKNOWLEDGMENTS}

The authors would like to thank Sabine Pailer, and Melanie Kaiser with the Medical University of Graz, and the Core Facility Experimental Biomodels, Division of Biomedical Research of the Medical University of Graz, 8036 Graz (Austria).

\section{CONFLICTS OF INTEREST}

The authors declare no conflicts of interest related to this study.

\section{REFERENCES}

1. Rockwood K, Fox RA, Stolee P, Robertson D, Beattie $B L$. Frailty in elderly people: an evolving concept. CMAJ. 1994; 150:489-95.

PMID: 8313261

2. de Lange T. Cell biology. Telomere capping--one strand fits all. Science. 2001; 292:1075-6. https://doi.org/10.1126/science.1061032 PMID:11352055

3. de Lange T. Shelterin: the protein complex that shapes and safeguards human telomeres. Genes Dev. 2005; 19:2100-10. https://doi.org/10.1101/gad.1346005

PMID: 16166375

4. Shay JW. Telomeres and aging. Curr Opin Cell Biol. 2018; 52:1-7.

https://doi.org/10.1016/j.ceb.2017.12.001

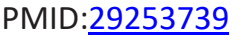

5. Meyne J, Ratliff RL, Moyzis RK. Conservation of the human telomere sequence (TTAGGG)n among vertebrates. Proc Natl Acad Sci U S A. 1989; 86:7049-53.

https://doi.org/10.1073/pnas.86.18.7049 PMID:2780561

6. Sharma S, Mukherjee AK, Roy SS, Bagri S, Lier S, Verma M, Sengupta A, Kumar M, Nesse G, Pandey DP, Chowdhury $\mathrm{S}$. Human telomerase is directly regulated by non-telomeric TRF2-G-quadruplex interaction. Cell Rep. 2021; 35:109154.

https://doi.org/10.1016/j.celrep.2021.109154 PMID: $\underline{34010660}$

7. Vinayagamurthy S, Ganguly A, Chowdhury S. Extratelomeric impact of telomeres: Emerging molecular connections in pluripotency or stemness. J Biol Chem. 2020; 295:10245-54.

https://doi.org/10.1074/jbc.REV119.009710 PMID:32444498

8. Gruber HJ, Semeraro MD, Renner W, Herrmann M. Telomeres and Age-Related Diseases. Biomedicines. 2021; 9:1335. https://doi.org/10.3390/biomedicines9101335 PMID:34680452

9. Robin JD, Ludlow AT, Batten K, Magdinier F, Stadler G, Wagner KR, Shay JW, Wright WE. Telomere position effect: regulation of gene expression with progressive telomere shortening over long distances. Genes Dev. 2014; 28:2464-76.

https://doi.org/10.1101/gad.251041.114

PMID:25403178

10. Baur JA, Zou Y, Shay JW, Wright WE. Telomere position effect in human cells. Science. 2001; 292:2075-7.

https://doi.org/10.1126/science.1062329

PMID:11408657

11. Herrmann M, Pusceddu I, März W, Herrmann W. Telomere biology and age-related diseases. Clin Chem Lab Med. 2018; 56:1210-22.

https://doi.org/10.1515/cclm-2017-0870

PMID:29494336

12. Njajou OT, Cawthon RM, Blackburn EH, Harris TB, Li R, Sanders JL, Newman AB, Nalls M, Cummings SR, Hsueh WC. Shorter telomeres are associated with obesity and weight gain in the elderly. Int J Obes (Lond). 2012; 36:1176-9. 
https://doi.org/10.1038/ijo.2011.196

PMID:22005719

13. Kiecolt-Glaser JK, Epel ES, Belury MA, Andridge R, Lin J, Glaser R, Malarkey WB, Hwang BS, Blackburn E. Omega-3 fatty acids, oxidative stress, and leukocyte telomere length: A randomized controlled trial. Brain Behav Immun. 2013; 28:16-24.

https://doi.org/10.1016/j.bbi.2012.09.004 PMID:23010452

14. Wang $Q$, Zhan $Y$, Pedersen NL, Fang F, Hägg S. Telomere Length and All-Cause Mortality: A Metaanalysis. Ageing Res Rev. 2018; 48:11-20.

https://doi.org/10.1016/i.arr.2018.09.002 PMID:30254001

15. Burchfield JG, Kebede MA, Meoli CC, Stöckli J, Whitworth PT, Wright AL, Hoffman NJ, Minard AY, Ma X, Krycer JR, Nelson ME, Tan SX, Yau B, et al. High dietary fat and sucrose results in an extensive and time-dependent deterioration in health of multiple physiological systems in mice. J Biol Chem. 2018; 293:5731-45.

https://doi.org/10.1074/jbc.RA117.000808 PMID:29440390

16. Dlouha D, Maluskova J, Kralova Lesna I, Lanska V, Hubacek JA. Comparison of the relative telomere length measured in leukocytes and eleven different human tissues. Physiol Res. 2014 (Suppl 3); 63:S343-50.

https://doi.org/10.33549/physiolres.932856 PMID:25428739

17. Hiam D, Smith C, Voisin S, Denham J, Yan X, Landen S, Jacques M, Alvarez-Romero J, Garnham A, Woessner MN, Herrmann M, Duque G, Levinger I, Eynon N. Aerobic capacity and telomere length in human skeletal muscle and leukocytes across the lifespan. Aging (Albany NY). 2020; 12:359-69. https://doi.org/10.18632/aging.102627 PMID:31901896

18. Demanelis K, Jasmine F, Chen LS, Chernoff M, Tong L, Delgado D, Zhang C, Shinkle J, Sabarinathan M, Lin H, Ramirez E, Oliva M, Kim-Hellmuth S, et al, and GTEx Consortium. Determinants of telomere length across human tissues. Science. 2020; 369:eaaz6876.

https://doi.org/10.1126/science.aaz6876

PMID:32913074

19. Cherif H, Tarry JL, Ozanne SE, Hales CN. Ageing and telomeres: a study into organ- and gender-specific telomere shortening. Nucleic Acids Res. 2003; 31:1576-83.

https://doi.org/10.1093/nar/gkg208

PMID:12595567

20. Werner C, Hanhoun M, Widmann T, Kazakov A, Semenov A, Pöss J, Bauersachs J, Thum T,
Pfreundschuh M, Müller P, Haendeler J, Böhm M, Laufs U. Effects of physical exercise on myocardial telomere-regulating proteins, survival pathways, and apoptosis. J Am Coll Cardiol. 2008; 52:470-82.

https://doi.org/10.1016/i.jacc.2008.04.034

PMID:18672169

21. Werner C, Fürster T, Widmann T, Pöss J, Roggia C, Hanhoun M, Scharhag J, Büchner N, Meyer T, Kindermann W, Haendeler J, Böhm M, Laufs U. Physical exercise prevents cellular senescence in circulating leukocytes and in the vessel wall. Circulation. 2009; 120:2438-47. https://doi.org/10.1161/CIRCULATIONAHA.109.8610 05

PMID: 19948976

22. Ludlow AT, Witkowski S, Marshall MR, Wang J, Lima LC, Guth LM, Spangenburg EE, Roth SM. Chronic exercise modifies age-related telomere dynamics in a tissue-specific fashion. J Gerontol A Biol Sci Med Sci. 2012; 67:911-26.

https://doi.org/10.1093/gerona/gls002

PMID:22389464

23. Ehrlenbach $S$, Willeit $P$, Kiechl $S$, Willeit J, Reindl $M$, Schanda K, Kronenberg F, Brandstätter A. Influences on the reduction of relative telomere length over 10 years in the population-based Bruneck Study: introduction of a well-controlled high-throughput assay. Int J Epidemiol. 2009; 38:1725-34.

https://doi.org/10.1093/ije/dyp273

PMID: 19666704

24. Müezzinler A, Zaineddin AK, Brenner H. A systematic review of leukocyte telomere length and age in adults. Ageing Res Rev. 2013; 12:509-19.

https://doi.org/10.1016/i.arr.2013.01.003

PMID:23333817

25. Berglund K, Reynolds CA, Ploner A, Gerritsen L, Hovatta I, Pedersen NL, Hägg S. Longitudinal decline of leukocyte telomere length in old age and the association with sex and genetic risk. Aging (Albany NY). 2016; 8:1398-415.

https://doi.org/10.18632/aging.100995

PMID:27391763

26. Huang Z, Liu C, Ruan Y, Guo Y, Sun S, Shi Y, Wu F. Dynamics of leukocyte telomere length in adults aged 50 and older: a longitudinal population-based cohort study. Geroscience. 2021; 43:645-54. https://doi.org/10.1007/s11357-020-00320-y PMID:33469834

27. Aviv A, Chen W, Gardner JP, Kimura M, Brimacombe M, Cao X, Srinivasan SR, Berenson GS. Leukocyte telomere dynamics: longitudinal findings among young adults in the Bogalusa Heart Study. Am J Epidemiol. 2009; 169:323-9. 
https://doi.org/10.1093/aje/kwn338

PMID: 19056834

28. Chen W, Kimura M, Kim S, Cao X, Srinivasan SR, Berenson GS, Kark JD, Aviv A. Longitudinal versus cross-sectional evaluations of leukocyte telomere length dynamics: age-dependent telomere shortening is the rule. J Gerontol A Biol Sci Med Sci. 2011; 66:312-9.

https://doi.org/10.1093/gerona/glq223

PMID:21310811

29. Lee $M$, Martin H, Firpo MA, Demerath EW. Inverse association between adiposity and telomere length: The Fels Longitudinal Study. Am J Hum Biol. 2011; 23:100-6.

https://doi.org/10.1002/ajhb.21109 PMID:21080476

30. Benetos A, Kark JD, Susser E, Kimura M, Sinnreich R, Chen W, Steenstrup T, Christensen K, Herbig U, von Bornemann Hjelmborg J, Srinivasan SR, Berenson GS, Labat C, Aviv A. Tracking and fixed ranking of leukocyte telomere length across the adult life course. Aging Cell. 2013; 12:615-21.

https://doi.org/10.1111/acel.12086

PMID:23601089

31. An R, Yan H. Body weight status and telomere length in U.S. middle-aged and older adults. Obes Res Clin Pract. 2017; 11:51-62.

https://doi.org/10.1016/j.orcp.2016.01.003 PMID:26895795

32. Prowse KR, Greider CW. Developmental and tissuespecific regulation of mouse telomerase and telomere length. Proc Natl Acad Sci U S A. 1995; 92:4818-22.

https://doi.org/10.1073/pnas.92.11.4818 PMID: $\underline{7761406}$

33. Golubovskaya VM, Filatov LV, Behe Cl, Presnell SC, Hooth MJ, Smith GJ, Kaufmann WK. Telomere shortening, telomerase expression, and chromosome instability in rat hepatic epithelial stem-like cells. Mol Carcinog. 1999; 24:209-17. https://doi.org/10.1002/(sici)10982744(199903)24:3<209::aid-mc7>3.0.co;2-f PMID: 10204805

34. Epel ES, Blackburn EH, Lin J, Dhabhar FS, Adler NE, Morrow JD, Cawthon RM. Accelerated telomere shortening in response to life stress. Proc Natl Acad Sci U S A. 2004; 101:17312-5.

https://doi.org/10.1073/pnas.0407162101 PMID:15574496

35. Richards JB, Valdes AM, Gardner JP, Kato BS, Siva A, Kimura M, Lu X, Brown MJ, Aviv A, Spector TD. Homocysteine levels and leukocyte telomere length. Atherosclerosis. 2008; 200:271-7. https://doi.org/10.1016/j.atherosclerosis.2007.12.035 PMID: $\underline{18280483}$

36. Paul L. Diet, nutrition and telomere length. J Nutr Biochem. 2011; 22:895-901. https://doi.org/10.1016/j.jnutbio.2010.12.001

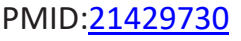

37. Botha M, Grace L, Bugarith K, Russell VA, Kidd M, Seedat $S$, Hemmings SM. The impact of voluntary exercise on relative telomere length in a rat model of developmental stress. BMC Res Notes. 2012; 5:697. https://doi.org/10.1186/1756-0500-5-697 PMID:23270390

38. de Vos-Houben JM, Ottenheim NR, Kafatos A, Buijsse B, Hageman GJ, Kromhout D, Giltay EJ. Telomere length, oxidative stress, and antioxidant status in elderly men in Zutphen and Crete. Mech Ageing Dev. 2012; 133:373-7.

https://doi.org/10.1016/j.mad.2012.04.003 PMID:22561920

39. Ludlow AT, Ludlow LW, Roth SM. Do telomeres adapt to physiological stress? Exploring the effect of exercise on telomere length and telomere-related proteins. Biomed Res Int. 2013; 2013:601368. https://doi.org/10.1155/2013/601368 PMID:24455708

40. Pusceddu I, Farrell CJ, Di Pierro AM, Jani E, Herrmann W, Herrmann $M$. The role of telomeres and vitamin $D$ in cellular aging and age-related diseases. Clin Chem Lab Med. 2015; 53:1661-78.

https://doi.org/10.1515/cclm-2014-1184

PMID:25803084

41. Arsenis NC, You T, Ogawa EF, Tinsley GM, Zuo L. Physical activity and telomere length: Impact of aging and potential mechanisms of action. Oncotarget. 2017; 8:45008-19.

https://doi.org/10.18632/oncotarget.16726 PMID:28410238

42. Ludlow AT, Gratidão L, Ludlow LW, Spangenburg EE, Roth SM. Acute exercise activates p38 MAPK and increases the expression of telomere-protective genes in cardiac muscle. Exp Physiol. 2017; 102:397410.

https://doi.org/10.1113/EP086189

PMID:28166612

43. Pusceddu I, Herrmann M, Kirsch SH, Werner C, Hübner U, Bodis M, Laufs U, Widmann T, Wagenpfeil S, Geisel J, Herrmann W. One-carbon metabolites and telomere length in a prospective and randomized study of B- and/or D-vitamin supplementation. Eur J Nutr. 2017; 56:1887-98.

https://doi.org/10.1007/s00394-016-1231-z PMID:27379829 
44. Boccardi M, Boccardi V. Psychological Wellbeing and Healthy Aging: Focus on Telomeres. Geriatrics (Basel). 2019; 4:25.

https://doi.org/10.3390/geriatrics4010025

PMID:31023993

45. Lai TP, Wright WE, Shay JW. Comparison of telomere length measurement methods. Philos Trans R Soc Lond B Biol Sci. 2018; 373:20160451.

https://doi.org/10.1098/rstb.2016.0451

PMID:29335378

46. Aubert G, Hills M, Lansdorp PM. Telomere length measurement-caveats and a critical assessment of the available technologies and tools. Mutat Res. 2012; 730:59-67.

https://doi.org/10.1016/i.mrfmmm.2011.04.003

PMID:21663926
47. Stansel RM, de Lange T, Griffith JD. T-loop assembly in vitro involves binding of TRF2 near the 3 ' telomeric overhang. EMBO J. 2001; 20:5532-40.

https://doi.org/10.1093/emboj/20.19.5532

PMID:11574485

48. Cawthon RM. Telomere measurement by quantitative PCR. Nucleic Acids Res. 2002; 30:e47.

https://doi.org/10.1093/nar/30.10.e47

PMID:12000852 


\section{SUPPLEMENTARY MATERIALS}

\section{Supplementary Table}

Supplementary Table 1. Relative telomere length, telomerase and shelterin gene expression in PBMCs and solid organs.

\begin{tabular}{|c|c|c|c|c|c|c|c|c|}
\hline \multirow[b]{2}{*}{ Cell/Tissue } & \multicolumn{2}{|c|}{$R T L$} & \multicolumn{2}{|c|}{$\begin{array}{c}\text { TERT } \\
m R N A \text { expression } \\
\end{array}$} & \multicolumn{2}{|c|}{$\begin{array}{c}\text { TERF-1 } \\
m R N A \text { expression }\end{array}$} & \multicolumn{2}{|c|}{$\begin{array}{c}\text { TERF-2 } \\
m R N A \text { expression }\end{array}$} \\
\hline & Young & Old & Young & Old & Young & Old & Young & Old \\
\hline PBMCs & $0.88 \pm 0.15$ & $0.92 \pm 0.11$ & & & & & & \\
\hline Spleen & $0.83 \pm 0.14$ & $0.88 \pm 0.21$ & $0.11 \pm 0.03$ & $0.13 \pm 0.06^{*}$ & $4.21 \pm 2.91$ & $4.26 \pm 1.65$ & $1.38 \pm 0.53$ & $1.85 \pm 0.53^{* \$ \$ \$}$ \\
\hline Liver & $0.99 \pm 0.16^{\$ \$}$ & $0.91 \pm 0.09$ & $3.55 \pm 1,92^{\$ \$ \$}$ & $3.99 \pm 2.33^{\$ \$ \$}$ & $8.52 \pm 4.50^{\$ \$ \$}$ & $19.08 \pm 15.30^{* * \$ \$ \$}$ & $3.95 \pm 2.24^{\$ \$ \$}$ & $6.84 \pm 3.24^{* * \$ \$ \$}$ \\
\hline Kidney & $0.96 \pm 0.13^{\S}$ & $0.91 \pm 0.11$ & $0.52 \pm 0.23^{\$ \$ \$}$ & $0.5 \pm 0.12^{\$ \$ \$}$ & $5.46 \pm 2.01$ & $7.54 \pm 3.13^{* \$ \$ \$}$ & $4.29 \pm 1.19^{\$ \$ \$}$ & $3.76 \pm 1.00^{\$ \$ \$}$ \\
\hline Muscle & $1.08 \pm 0.30^{\$ \$ \$}$ & $0.96 \pm 0.14$ & $0.09 \pm 0.05$ & $0.21 \pm 0.20^{*}$ & $6.12 \pm 2.88$ & $7.89 \pm 3.63^{\$ \$ \$}$ & $4.46 \pm 1.18^{\$ \$ \$}$ & $5.04 \pm 1.82^{\$ \$ \$}$ \\
\hline Aorta & $0.98 \pm 0.15^{\S}$ & $0.76 \pm 0.11^{* * * \$ \$ \$}$ & $0.24 \pm 0.20^{\$ \$}$ & $0.2 \pm 0.12^{\$}$ & $1.83 \pm 1.30^{\$ \$ \$}$ & $1.28 \pm 0.75^{\$ \$ \$}$ & $2.23 \pm 1.06^{\$ \$}$ & $1.35 \pm 0.37^{* * \$ \$ \$}$ \\
\hline Intestine & $0.64 \pm 0.26^{\$ \$ \$}$ & $0.71 \pm 0.27^{\$ \$}$ & $0.04 \pm 0.03^{\$ \$ \$}$ & $0.05 \pm 0.04^{\$ \$ \$}$ & $1.24 \pm 0.91^{\$ \$ \$}$ & $1.25 \pm 0.77^{\$ \$ \$}$ & $0.68 \pm 0.28^{\$ \$ \$}$ & $0.70 \pm 0.54^{\$ \$ \$}$ \\
\hline Brain & $0.84 \pm 0.09$ & $0.88 \pm 0.17$ & $0.21 \pm 0.16^{\S}$ & $0.16 \pm 0.08$ & $5.93 \pm 2.19^{\$ \$}$ & $5.28 \pm 2.00$ & $7.59 \pm 3.34^{\$ \$ \$}$ & $5.79 \pm 2.18^{\$ \$}$ \\
\hline Lung & $0.76 \pm 0.14^{\$ \$ \$}$ & $0.85 \pm 0.14^{* \$}$ & $0.14 \pm 0.07$ & $0.16 \pm 0.04$ & $8.33 \pm 4.20^{\$ \$ \$}$ & $4.19 \pm 2.30^{* * *}$ & $1.99 \pm 0.69^{\$ \$}$ & $2.79 \pm 1.01^{* * \$ \$ \$}$ \\
\hline Visceral fat & $0.83 \pm 0.14$ & $0.92 \pm 0.16^{*}$ & $0.15 \pm 0.03^{\$ \$ \$}$ & $0.26 \pm 0.09^{* * * \$ \$ \$}$ & $1.4 \pm 0.41^{\$ \$}$ & $3.26 \pm 2.03^{* * *}$ & $1.93 \pm 0.46^{\$ \$ \$}$ & $2.22 \pm 0.56^{\$}$ \\
\hline
\end{tabular}

Data are presented as means \pm SD; significant differences were highlighted between young and adult animals $\left(^{*}\right)$, and vs. PBMCs for RTL $(\$)$ or spleen for gene expression analysis $\left({ }^{\$}\right)$ in either young or adult animals. ${ }^{*} p<0.05,{ }^{* *} p<0.01,{ }^{* * *} p<0.001$ vs. young; ${ }^{\$} p<0.05,{ }^{\$ \$} p<0.01,{ }^{\$ \$ \$} p<0.001$ vs. reference tissue. 